\begin{tabular}{|c|c|}
\hline $\begin{array}{l}\text { Perspectivas teóricas para el estudio de los movimientos sociopolíticos en América } \\
\text { Latina: ¿cambio de época o década perdida? }\end{array}$ & Titulo \\
\hline Modonesi, Massimo - Autor/a; Iglesias, Mónica - Autor/a; & Autor(es) \\
\hline $\begin{array}{l}\text { De Raíz Diversa. Revista Especializada en Estudios Latinoamericanos (Vol. } 3 \text { no. } 5 \\
\text { ene-jun 2016) }\end{array}$ & En: \\
\hline México D.F. & Lugar \\
\hline $\begin{array}{l}\text { Programa de Posgrado en Estudios Latinoamericanos, Universidad Nacional } \\
\text { Autónoma de México }\end{array}$ & Editorial/Editor \\
\hline \multirow[t]{2}{*}{2016} & Fecha \\
\hline & Colección \\
\hline $\begin{array}{l}\text { Teoría social; Sociología política; Acción colectiva; Movimientos sociales; América } \\
\text { Latina; }\end{array}$ & Temas \\
\hline Artículo & Tipo de documento \\
\hline $\begin{array}{l}\text { "http://biblioteca.clacso.edu.ar/Mexico/ppel-unam/20160630030616/4._Perspectivas_teoricas_para_el_estudiio_de_los_movimientos_soci } \\
\text { opoliticos_en_America_Latina__cambio_de_epoca_o_decada_perdida._-Massimo_Modonesi_Monica_lglesias.pdf" }\end{array}$ & URL \\
\hline $\begin{array}{l}\text { Reconocimiento-No Comercial-Sin Derivadas CC BY-NC-ND } \\
\text { http://creativecommons.org/licenses/by-nc-nd/2.0/deed.es }\end{array}$ & Licencia \\
\hline
\end{tabular}

Segui buscando en la Red de Bibliotecas Virtuales de CLACSO http://biblioteca.clacso.edu.ar

Consejo Latinoamericano de Ciencias Sociales (CLACSO)

Conselho Latino-americano de Ciências Sociais (CLACSO)

Latin American Council of Social Sciences (CLACSO)

www.clacso.edu.ar

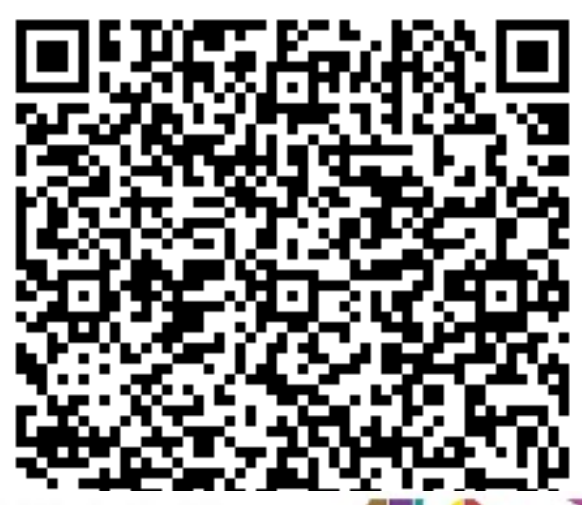

Consejo Latinoamericano de Ciencias Sociales

Conselho Latino-americano de Ciências Sociais

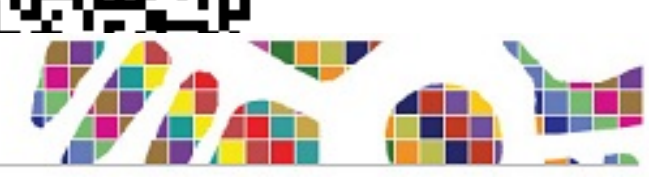




\title{
Perspectivas teóricas para el estudio de los movimientos sociopolíticos en América Latina: ¿cambio de época o década perdida?*
}

\author{
Massimo Modonesi $^{* *}$ Y MóniCa Iglesias ${ }^{* * *}$
}

RESUMEN: Durante aproximadamente una década, que abarca el último lustro del siglo xx y el primero del xxI, América Latina vivió un ciclo de movilización sociopolítica de extraordinario vigor, a la luz del cual se produjo una notable efervescencia teórica y conceptual en el campo de los estudios de los movimientos sociopolíticos, la acción colectiva y los procesos de subjetivación política. En este artículo sostenemos que, pese a que es posible reconocer ejercicios sugerentes de problematización teórica, no se ha configurado aún un paradigma alternativo para la comprensión de los procesos de movilización sociopolítica que pudiera desplazar, en los análisis académicos y en el campo intelectual, a las teorías y enfoques predominantes, de origen europeo y norteamericano. Para explicar la relativa inconsistencia, débil articulación e insuficiente proyección de esos esfuerzos teóricos ensayamos algunas hipótesis que se relacionan con factores históricos y estructurales de la configuración de las ciencias sociales en la región, y con actitudes y posturas epistemológicas y políticas de los académicos críticos latinoamericanos que traslucen una nueva conceptualización sobre los movimientos sociales y la construcción del conocimiento.

Palabras Clave: movimientos sociales, acción colectiva, sociología política, teoría social.

Abstract: During almost a decade that comprises of the last part of the $20^{\text {th }}$ century and the first years of the $21^{\text {st }}$ century, Latin America lived an extraordinarily vigorous cycle of socio-political mobilization. In light of these events a remarkable theoretical and conceptual effervescence in the field of the sociopolitical movements studies, the collective action and the processes of political subjectivization was produced. In this article, the authors argue that although it is possible to recognize suggestive exercises about theoretical problematization, an alternative paradigm to understand the processes of social and political mobilization that could displace, in academic analysis and in the

\footnotetext{
Este artículo forma parte del proyecto de investigación PAPIIT-UNAM IN-303813, "Subalternidad, antagonismo y autonomía en los movimientos socio-políticos en México y América Latina", coordinado por Massimo Modonesi.

** Historiador y sociólogo; profesor titular de la Facultad de Ciencias Políticas y Sociales de la UNAM <modonesi@hotmail.com>.

*** Socióloga, doctora en Estudios Latinoamericanos de la UNAM <monicaiglesias@ hotmail.com>.
} 
intellectual field, the prevailing theories and approaches from Europe and the us has not been set up yet. To explain this relative inconsistency, weak coordination and insufficient projection of these theoretical efforts, the authors test some hypotheses that relate to historical and structural factors shaping the social sciences in the region, and to epistemological and political attitudes and positions of Latin American critical scholars that foreshadow a new conceptualization of social movements and the construction of knowledge.

KEYWORDS: Keywords: social movements, collective action, political sociology, social theory.

Recibido: 06 de mayo de 2015. ACEPtado: 20 de mayo de 2015.

A

lo largo de diez años, desde mediados de los años noventa hasta mediados de la siguiente década, América Latina fue el escenario de la irrupción de una serie de luchas populares antineoliberales, un ciclo de movilización sociopolítica -caracterizado por el crecimiento sostenido de protestas siempre más politizadas y extendidas-. Esta acumulación de fuerzas permitió pasar de la subalternidad y la resistencia a posturas y prácticas antagonistas que lograron modificar los equilibrios políticos generales cuando, en el primer lustro del siglo xxI, se intensificaron y ampliaron las luchas dando lugar a acontecimientos destituyentes, instituyentes y constituyentes que debilitaron y desplazaron a las fuerzas políticas neoliberales forzando un giro "progresista" en el gobierno de la mayoría de los países de la región (Modonesi, 2008).

Este ciclo de luchas y movimientos sociales con vocación, proyección y eficacia política ha, sin duda, revitalizado el pensamiento crítico latinoamericano y, en este marco, reposicionado el estudio de los movimientos sociales y la acción colectiva y, como trataremos de sostener, trastocado sus pautas. Múltiples y diversos estudios surgidos en los espacios académicos, y fuera de ellos, han buscado caracterizar esas formas emergentes de protesta y de movilización, la especificidad de los actores sociales que las protagonizaban, sus identidades, el tipo de reivindicaciones enarboladas, sus capacidades organizativas y los alcances y límites de sus horizontes emancipatorios. El notable aumento cuantitativo de los estudios en torno a estas temáticas puede medirse en el crecimiento exponencial de ponencias en los Congresos de AlAS y LASA, de seminarios, cursos, grupos de trabajo y publicaciones sobre movimientos sociales, así como en la creación de diversos observatorios de conflicto social (entre los que 
destacó el Observatorio Social de América Latina de CLAcso y la revista que le correspondía). ${ }^{1}$

Sin embargo, dos décadas después del inicio de la emergencia de luchas sociales que provocaron la crisis del neoliberalismo y que abrieron procesos de cambio y reformas políticas, resulta oportuno preguntarse por el alcance cualitativo, por la acumulación y el impacto teóricos que pudieron resultar de la atención y los esfuerzos analíticos centrados en los movimientos sociales y políticos. Dicho de otra manera, es pertinente indagar en qué medida el llamado cambio de época, de clima político, impulsó una equivalente transformación epocal en las ciencias sociales de la región, en particular en la sociología política y los estudios de la acción colectiva y los movimientos sociales, a contracorriente del giro conservador de la transitología que produjo una interpretación a-conflictiva de la política, vinculada a la preocupación por la gobernabilidad, la representación y los procesos de institucionalización, generalmente focalizada en el estudio de los sistemas electorales y de partido.

La hipótesis fundamental que queremos esbozar es que, a pesar de las condiciones particularmente propicias, que debieron y pudieron favorecer un florecimiento de nuevos enfoques y aproximaciones y un proceso de renovación teórica, se aprecian sólo aportaciones parciales y, aunque pudieran rastrearse ejercicios sugerentes, no se observan las condiciones para que ocurra un cambio de paradigmas respecto de las teorías dominantes ${ }^{2} \mathrm{o}$

1 También ha sido notable el florecimiento de universidades de corte popular preocupadas por la construcción de un conocimiento social desde y para los movimientos sociales: Universidad Popular Madres de Plaza de Mayo (Argentina), Escola Nacional Florestan Fernandes (Brasil), Unipop-Instituto Universidade Popular (Brasil), Universidad de la Tierra (México), Universidad Intercultural de las Nacionalidades y Pueblos Indígenas Amawtay Wasi (Ecuador), etc.

2 Nos referimos a los paradigmas de la acción colectiva de mayor circulación, no sólo en América Latina. Estos son, a grandes rasgos, tres. En primer lugar, la Teoría de la Movilización de Recursos - TMR- (McCarthy y Zald), que recupera los principios neoutilitaristas de la lógica estratégica y los cálculos coste-beneficio para aplicarlos a los procesos de movilización, enfatizando la dinámica interna del movimiento, esto es, su capacidad de captar y movilizar recursos para presionar a las autoridades en pro de una demanda específica. En segundo lugar, el enfoque de las Estructuras de Oportunidad Política (EOP), del "proceso político" o la "política contenciosa" (Tilly y Tarrow), que constituye un esfuerzo de corte tanto histórico como estructural por comprender el desarrollo de la acción colectiva, y los factores que facilitan o inhiben la ocurrencia de eventos de protesta, en estrecha interdependencia con el papel del Estado. Y, en tercer lugar, el paradigma de los Nuevos Movimientos Sociales, cuyo desarrollo se ha dado principalmente en Europa (donde es posible distinguir varias "escuelas": la francesa, de Touraine, la alemana de Offe y Haber- 
que se asiente un piso firme de teorizaciones como antesala de la elaboración de sólidas alternativas teóricas. Si bien los debates y las aportaciones teóricas fueron importantes y significativos y merecen ser reconocidos y destacados, a nuestro parecer, no alcanzaron o no alcanzan todavía para conformar cuerpos teóricos susceptibles de disputar a las teorías dominantes tanto el campo académico en el cual se desarrollan las investigaciones como el más amplio campo intelectual donde se gestan las coordenadas generales de las principales interpretaciones sobre los movimientos sociales.

Un florecimiento teórico implicaría que, desde la tradición del pensamiento crítico latinoamericano, se emprendiera amplia y difusamente la tarea de construir o reconstruir deliberada y sistemáticamente conceptos o perspectivas teóricas - aun de "medio alcance"- para explicar esas luchas y movimientos sociales que, a todas luces, rebasaron la capacidad explicativa de los marcos teóricos dominantes y desafiaron sus postulados fundamentales. Constatamos, en efecto, un desfase entre la difundida insatisfacción que producen esas propuestas teóricas y la escasez o virtual ausencia -según la menor o mayor severidad en su evaluación-, de perspectivas alternativas que cumplan tanto con ciertos requisitos de solidez teórica como con la posibilidad de convertirse operativamente en apuestas metodológicas.

Al mismo tiempo, antes de interrogarnos sobre estos límites, es necesario revisar y valorar el vaso medio lleno de la producción y los debates teóricos que surgieron al calor de la conflictualidad y las movilizaciones que sacudieron el escenario político a partir de mediados de los años ' 90 .

En efecto, la evidencia de un proceso político que alcanzaba proyección regional propició una preocupación latinoamericana en la investigación sobre movimientos sociales, lo cual redundó en una mayor sensibilidad supranacional y en el incremento de estudios comparativos. ${ }^{3}$ Por obvias

mas, la italiana, de Melucci, y la holandesa, de Klandermas), y que partió enfatizando las dimensiones de ruptura de los NMs frente al movimiento obrero, en relación con las formas de organización y de acción, los valores y la identidad de los actores respecto de reivindicaciones fundamentalmente culturales, de "reconocimiento". No incluimos la corriente del frame analysis (Benford-Snow) no porque no se haya difundido ampliamente sino porque su alcance más limitado no lo configura como un paradigma general de comprensión de los fenómenos y procesos de la acción colectiva.

3 Generalmente dos o tres casos. Hay que señalar que existen pocos trabajos en este periodo (1995-2015) que aborden la problemática de los movimientos sociales tratando de construir una mirada de conjunto (Ceceña, 2002; Seoane, 2003; Bruckmann y Dos Santos, 2005; Dávalos, 2005; Seoane, Taddei y Algranati, 2006; Sader, 2008; Rebón y Modonesi, 
razones, los esfuerzos parecen haberse concentrado en aquellos países en los que el desafío planteado por los movimientos sociales ha sido más profundo: Argentina, Bolivia, Ecuador; y en algunas experiencias particulares en países del peso de Brasil y México, en donde habían sido pioneros los análisis sobre el Movimiento de los Trabajadores Sin Tierra (Msт) y el Ejército Zapatista de Liberación Nacional (EZLN). Asumiendo como premisa cierta correspondencia entre ciclos de movilización y procesos de construcción del conocimiento, a mayor importancia e impacto de los movimientos, más esfuerzos y resultados en términos de estudios y análisis, sin olvidar el efecto multiplicador ligado a la densidad de las instituciones universitarias que, para contrastar los casos emblemáticos, es muy distinta en Brasil, México y Argentina en comparación con Bolivia, Ecuador y Venezuela. No es posible desagregar cabalmente en este ensayo el análisis de los saldos nacionales de las investigaciones sobre movimientos nacionales, los cuales por lo demás tuvieron temporalidades, ritmos y focos de atención diferentes, a los que nos referiremos parcialmente en las generalizaciones que sostendremos a continuación. ${ }^{4}$

La exposición de nuestros argumentos empezará por reconocer e identificar las principales aportaciones en torno a algunos focos y debates temáticos que permiten valorar ciertos giros teóricos para posteriormente centrarnos en la problematización del estado y la proyección de las teorizaciones, es decir primero veremos los alcances y posteriormente los límites de las tendencias en curso.

2011). En una primera aproximación a un recorte bibliográfico no parece adecuado excluir por una simple cuestión nominalista, aquellos trabajos que no se refieren explícitamente a los movimientos sociopolíticos - toda vez que la falta de consenso sobre cómo denominar a las acciones de protesta y de movilización constituye uno de los rasgos de la producción latinoamericana reciente-, pero que abordan el problema de la constitución de subjetividades políticas y de la transformación social y que, por lo tanto, dialogan implícita o explícitamente con los estudios específicos sobre movimientos sociales.

4 No existen a la fecha estados del arte por país que permitan soportar el análisis transversal que queremos sostener. Reconocemos, por lo tanto, que nuestras reflexiones se basan sobre una mirada de conjunto no exhaustiva ni sistematizada y, por ende, con un alto grado de arbitrariedad. Al mismo tiempo las consideramos válidas como hipótesis de trabajo para futuras investigaciones a profundidad y como apuntes que pretenden suscitar una reflexión crítica, abrir un debate, sin negar su alcance polémico. 


\section{SEÑALES DE UN CAMBIO DE ÉPOCA: FOCOS, DEBATES Y GIROS TEÓRICOS}

Hay que resaltar los esfuerzos del pensamiento crítico latinoamericano para renombrar y resignificar ciertas dimensiones, aspectos o características de los conflictos sociales y de los actores sociopolíticos, que aparecen como novedosas o fueron renovadas respecto a décadas anteriores en América Latina y también en relación con procesos de conflictualidad social en otras regiones del planeta. La tendencia predominante en las ciencias sociales latinoamericanas ha sido realzar el carácter distintivo y novedoso de los movimientos sociales latinoamericanos recientes, lo cual trasluciría los límites de las teorías europeas y norteamericanas sobre movimientos sociales y desafiaría la comprensión y conceptualización de esos fenómenos a partir de enfoques alternativos.

A nivel temático, los principales focos y debates teóricos emergentes que queremos destacar se refieren a: 1) la territorialidad de los conflictos sociopolíticos recientes; 2) la emergencia política de las comunidades indígenas y, con ellas, la forma comunitaria como dinámica de construcción de subjetividades políticas alternativas; 3 ) la construcción de autonomías como experiencia cotidiana -que se expresa en la prácticas autogestionarias de muchos colectivos y organizaciones sociales- y como horizonte emancipador; y, por último, 4) la relación con el Estado y replanteamiento de su lugar en la estrategia emancipatoria, que conlleva una mutación en la forma de hacer política de los movimientos sociales latinoamericanos.

La selección de estos nudos problemáticos se justifica por su emergencia cualitativa y cuantitativamente porque se trata de temas que ocuparon el centro del debate político, intelectual y académico y, por ello, también fueron objeto de una extensa producción. ${ }^{5}$ Por otra parte, se trata de dimensiones que tienden a conectarse y, por lo tanto, serían susceptibles de articularse, constituyendo la plataforma problemática sobre la cual podrían y deberían montarse las coordenadas analíticas de nuevas o renovadas

\footnotetext{
5 Es indicativo de estas tendencias el análisis de los materiales producidos y los grupos de trabajo impulsados por CLACSO, ya que resultó un lugar de convergencia latinoamericana con un sello progresista, marcado por el interés por la emergencia de los movimientos antineoliberales y el cambio de época, dirigido por dos intelectuales claramente identificados y comprometidos con las demandas que enarbolaban las luchas. Para una sistematización anterior de los principales ejes temáticos que articularon la discusión en relación con los movimientos sociales latinoamericanos en las últimas décadas, véase el $\mathrm{n}^{\circ} 30$ de la revista OSAL, y específicamente los trabajos de Iglesias (2011) y Parra (2011).
} 
elaboraciones teóricas. Si bien estas discusiones se sumaron a una agenda existente, no la desplazaron, aunque hay que reconocer que, en ciertos puntos y aspectos, hubo colisión y empujes con relación a la centralidad o primacía de una dimensión u otra. No nos referiremos a otras dimensiones o temas más clásicos, aunque sea posible rastrear también en estos terrenos novedades y aportaciones, en la medida en que estamos tratando de poner en evidencia un rasgo de época más que hacer un recuento puntual.

\section{TERRITORIALIDAD}

Quizás la dimensión analítica emergente más aceptada y difusa ha sido la de la territorialización de los conflictos sociopolíticos, hasta el punto de que algunos autores han considerado que ése es el rasgo constitutivo de los movimientos sociales latinoamericanos recientes (Porto-Gonçalves, 2003, 2005 y 2008; Svampa, 2007 y 2012, entre otros), los cuales han sido definidos, específicamente, como movimientos socio-territoriales o socio-ambientales. La importancia de la construcción de nuevas territorialidades (Zibechi, 2003), tanto en el campo como en la ciudad, radica en que el territorio se concibe como un espacio de reapropiación, resistencia, re-significación y también de creación de nuevas relaciones sociales (Svampa, 2007). Implica la configuración de nuevas relaciones y de nuevas formas organizativas; no es sólo reivindicación de tierra (como "bien productivo") o de "vivienda" (como "bien habitacional") sino de espacios para reconstruir relaciones sociales más solidarias, comunitarias, que piensan el territorio de manera integral, soldado con la cultura y la posibilidad de una vida digna (Svampa y Pereyra, 2003).

El énfasis en la dimensión territorial de los conflictos ha considerado también el examen de la fase del capitalismo neoliberal y del predominio del modelo de reprimarización de la economía, que supuso la intensificación de los procesos de extracción y explotación de los recursos naturales. Este modelo implicó, en la ciudad, la privatización y la inclusión en las lógicas mercantiles de sectores urbanos (y de servicios), que anteriormente habían permanecido al margen del mercado, originando la expulsión de ellos (gentrificación y elitización) de amplias capas de la sociedad; y, en el campo, el recrudecimiento de los procesos de expansión del modo de producción capitalista a nuevas regiones y territorios antes "inexplorados". La minería a cielo abierto, las represas, la construcción de otras 
grandes infraestructuras, etc. están en el centro de muchos de los conflictos sociopolíticos de las últimas décadas. El análisis de esta dimensión parece fundamental porque permite vincular el examen de los procesos de subjetivación política con los aspectos estructurales referidos al modo de producción, tendiendo puentes entre dos perspectivas que a menudo han tendido a pensarse como excluyentes. De hecho, la tensión entre la especificidad y la búsqueda de una identidad compartida, comprobable empíricamente, parece reproducirse a nivel de la teoría, entre aquellos enfoques que privilegian y valorizan la particularidad de los fenómenos en cuestión y los que buscan construir una mirada que resalte las confluencias y articulaciones. La "base" estructural conformada a partir de los procesos de reprimarización de la economía, intensificación de la explotación de los recursos naturales, deslocalización productiva, extensión de la explotación laboral más allá de la "fábrica", privatización de los servicios básicos, etc. ha sido trabajada como el piso común sobre el que tender puentes de comunicación entre las distintas experiencias referidas a esos procesos.

La instalación de los llamados gobiernos progresistas fruto, en forma más o menos directa, de esos procesos de movilización sociopolítica, no ha disminuido la importancia de la dimensión territorial de los conflictos $y$, en algunos casos, parece haberla acrecentado. Así, los análisis sobre el efecto del aumento del precio mundial de algunos commodities en las políticas públicas, la caracterización de la política económica y del horizonte estratégico de esos gobiernos como neo-desarrollismo y neo-extractivismo, siguen señalando al territorio $-\mathrm{y}$ el tipo de relaciones que lo construyen- como el centro de las dificultades que presenta la relación entre gobiernos "progresistas" y movimientos sociales (Svampa, 2008).

\section{COMUNIDAD}

La dimensión territorial se relaciona, a su vez, con el protagonismo que han adquirido los movimientos indígenas en este nuevo ciclo de conflictualidad sociopolítica. Efectivamente la movilización de muchas comunidades indígenas se produce como respuesta a los procesos de privatización y de sobreexplotación de sus recursos naturales, en una estrategia del capital que se ha definido como "acumulación por desposesión" (Harvey, 2004). Este concepto ha sido retomado por varios analistas latinoamericanos (Svampa, 2010) y, en algunos casos, reformulado como "acumulación por 
despojo" (Seoane, 2012). La implantación y profundización de las prácticas de despojo ha sido posible (o ha requerido) el despliegue de un nuevo imperialismo o de un "neoliberalismo de guerra" (González Casanova, 2002) o "neoliberalismo armado" (Taddei, 2002) que se ha caracterizado por la creciente militarización de las relaciones sociales.

Ese proceso se ha analizado también como la reedición, y el carácter recurrente, de los procesos de "acumulación primitiva", por cuanto éstos suponen la división de comunidades, la privatización y expropiación de tierras y de otros recursos naturales y el saqueo, siempre que el capitalismo requiere dar un nuevo impulso a su afán acumulativo. Así considerada, la llamada acumulación primitiva destruyó el poder de las comunidades rurales, debilitó las relaciones sociales basadas en la colaboración, desproveyó a los sectores populares de los medios de subsistencia garantizados por el usufructo de los commons e introdujo profundas divisiones en el interior del proletariado -como las de género, "raza" y edad- que sirven para "intensificar y ocultar la explotación" (Federici, 2010: 90). Varios trabajos latinoamericanos abordan los procesos de expropiación y despojo de las comunidades indígenas y campesinas - "campesindias", a decir de Bartra (2010)- a partir de esas claves analíticas; de ahí la importancia que ha adquirido el concepto de "commons" o de "lo común" en las luchas anticapitalistas actuales en la región. Y no sólo en relación con el ámbito rural, sino también frente a las estrategias de "cercamiento" - de territorios, de cuerpos y de saberes- experimentadas en las ciudades.

La emergencia política de las comunidades indígenas en los procesos de conflictualidad sociopolítica en algunos países de la región ha apremiado el cuestionamiento acerca de los procesos de constitución de los actores protagonistas de la transformación social. A la par de un "juicio al sujeto" (Guido y Fernández, 1990) en América Latina, que supuso el cuestionamiento del movimiento obrero en su configuración tradicional, y el abandono de la noción de clase social (Vilas 1995), el influjo de la teoría de los nuevos movimientos sociales insufló la idea de la radical diferencia entre el "viejo" movimiento obrero y los "nuevos" movimiento sociales. Pero varios autores latinoamericanos han cuestionado esta contraposición -toda vez que cuantitativamente las organizaciones laborales han seguido teniendo un peso significativo en la organización de la protesta, como han constatado los comités de seguimiento y análisis de coyuntura de OSAL (Seoane, Taddei y Algranati, 2011) - y han puesto en duda que el enfoque 
europeo de los Nuevos Movimientos Sociales sirva para caracterizar la novedad de la conflictualidad social latinoamericana reciente, definida por la preeminencia de los sectores populares y no de las clases medias. Además, se han realizado esfuerzos por repensar la condición obrera de las clases populares latinoamericanas, y el papel del trabajo en los procesos actuales de conflicto social y político (Antunes, 2013). ${ }^{6}$

En los análisis sobre movimientos sociales en la actualidad se reproduce, aunque no siempre de manera explícita, las tensiones entre los enfoques que valorizan los procesos de constitución subjetiva y aquellos que enfatizan los condicionamientos económico-estructurales. Una noción de la clase social como un concepto esencialmente estructural y socio-económico dificulta su articulación con la noción de movimientos sociales, que enfatiza la dimensión cultural y el carácter procesual y relacional de su constitución. En cambio, una comprensión de la clase también en términos relacionales y socio-políticos facilita establecer vinculaciones entre ambos conceptos.

Por otra parte, la emergencia de los movimientos indígenas no se sitúa exclusivamente en el campo del reconocimiento de su identidad y cultura, y de su inclusión y representación, sino que cuestiona la propia conformación del Estado liberal y de las pretensiones de universalidad de éste, condición que implica repensar el Estado, la política, y la democracia representativa (Dávalos, 2005). La movilización indígena combina la dimensión identitaria con la reivindicación económica, y no puede reducirse a una sola de estas dimensiones, sin riesgo de incurrir en determinismos e incomprensiones severas del fenómeno en cuestión. El protagonismo indígena es examinado, entonces, no sólo en relación con la dimensión identitaria, como búsqueda del reconocimiento, sino también como respuesta a los procesos de expropiación y saqueo de los recursos naturales y como reserva y prefiguración de otro tipo de relaciones sociales y de vinculación con la naturaleza. En ese sentido, algunos autores han revalorizado la noción de comunidad como dispositivo político (García Linera, 2001 y 2009; Prada, 2008; Gutiérrez, 2009), anclados en su conocimiento vivencial de las comunidades indígenas andinas, recuperando aspectos fundamentales de la "forma comunidad" -en términos de García Linera- para pensar la

6 La preeminencia de la dimensión "popular" para caracterizar a los movimientos sociales latinoamericanos se ha verificado en la revitalización de la hipótesis nacional-popular (ver toda la corriente que remite a Ernesto Laclau pero también García Linera, entre otros). 
transición del capitalismo a otro modo de existencia centrado en la valorización de la vida y de la naturaleza -condensado en la expresión sumak kawsay o suma qamaña-. Estos trabajos exploran la vinculación existente entre las características de la comunidad (indígena) y las más recientes movilizaciones que han protagonizado los pueblos andinos.

\section{AUTONOMÍA}

La dimensión comunitaria de los movimientos sociales latinoamericanos trasciende el ámbito de las comunidades indígenas y se pone de manifiesto también en otras experiencias rurales y urbanas vinculadas con la búsqueda de autonomía y las prácticas autogestionarias. La noción de autonomía, exaltada desde algunas perspectivas como la única forma de transformación sustantiva de la sociedad, se ha complejizado al entender que no es sólo una forma organizativa sino también un fin estratégico. De esta manera, la autonomía se entiende como la independencia de los movimientos sociales respecto de los partidos políticos y de los gobiernos, como la preservación de espacios y dinámicas de decisión propias, pero también como ampliación de las capacidades del movimiento en relación con la construcción de la vida -educación, salud, vivienda, autogobierno, etc.- que constituyen fines en sí mismas. Sin embargo, desde otras perspectivas, y a menudo desde los propios movimientos sociales, la autonomía aparece no tanto como una búsqueda sino como una condición forzada, de carácter defensivo, aunque a posteriori pueda ser valorada y reclamada conscientemente. En todo caso, la preeminencia de lógicas autónomas y prácticas autogestionarias sugiere una mirada desde los movimientos sociales más crítica que en el pasado respecto de las posibilidades de transformación mediante la institucionalidad gubernamental y se traduce en una actitud más vigilante en relación con sus representantes.

Las dimensiones territoriales y comunitarias se vinculan con los esfuerzos por profundizar la autonomía de los movimientos sociales. Las prácticas autogestionarias, a menudo forzosas, permitieron la reconstrucción de lazos sociales erosionados por las políticas neoliberales, la reducción del Estado, y la hegemonía -conflictiva- que alcanzó el neoliberalismo (con sus valores de individualismo y competencia) en la primera mitad de la década de los 90. La autonomía y la construcción de espacios autogestionarios es también la respuesta a la deslocalización y erosión de la 
territorialidad del movimiento obrero tradicional anclado a la fábrica. La diversidad, fragmentación e inestabilidad del mundo del trabajo, ha provocado según algunos autores un proceso de ampliación de los procesos de trabajo hacia otras esferas de la vida, transgrediendo la fábrica como el lugar privilegiado de la explotación laboral (Ceceña, 2002: 11).

Los movimientos sociales latinoamericanos han sido concebidos, no como medios para producir cambios en la esfera pública y estatal, sino como fines en sí mismos, como formas de construir relaciones sociales alternativas y espacios públicos o comunitarios no estatales (Ouviña, 2002). Los movimientos ocupan y se reapropian de territorios y construyen desde una idea comunitaria de la política (que supone mayor horizontalidad, corresponsabilidad, rotación de cargos, acción directa no sólo en su expresión más disruptiva sino como el acto de "asumir en sus propias manos" las tareas de transformación) la construcción de otros modos de vivir y de relacionarse. Esta lectura de los nuevos movimientos sociales latinoamericanos ha enfatizado el carácter de germen de otros mundos posibles, que arraigan y crecen en esos "espacios" urbanos o rurales "liberados", en los que se construyen otros sujetos sociopolíticos y otras formas de organización social (Zibechi, 2007; Ceceña, 2008; González Casanova, 2009). Asimismo, la construcción de autonomías como medio y como fin, como una estrategia de reapropiación del territorio y de construcción de alternativas sociales implica un proceso de politización de lo cotidiano (Zibechi, 2003 y 2006); el territorio, el barrio o la comunidad, se convierten en espacios privilegiados de subjetivación política.

\section{POLÍTICA Y PODER}

La búsqueda de autonomía y las prácticas autogestionarias de muchas experiencias de organización y movilización se relaciona, además, con la problemática del poder y de la política. El énfasis en la novedad de los movimientos sociales latinoamericanos recientes estaría signado por la enérgica emergencia de actores sociopolíticos anteriormente marginados (frente a la centralidad política del movimiento obrero), así como por formas de acción, de organización y de participación política y ejercicio de la autoridad, también distintas, y en principio más democráticas (Giarraca, 2012). La denuncia del autoritarismo y vanguardismo presentes en algunas organizaciones tradicionales, y la lógica utilitarista de los partidos 
políticos, el cuestionamiento de la estrategia de la "toma del poder" y de la lógica representativa de la democracia, la valoración del principio del "mandar obedeciendo", la certeza en la transformación de la realidad como un ejercicio permanente y cotidiano, etc. habría permitido la emergencia de una política alternativa y de una concepción distinta de la democracia (como democracia directa o participativa). Una política que ha sido adjetivada como "salvaje" o "plebeya" (Tapia, 2008).

Varios estudios destacan que los nuevos movimientos sociales latinoamericanos se caracterizan por la acción directa, las formas de acción preferentemente no institucionales, la democracia participativa o de base, la política como una actividad no-profesional, etc. La forma asamblearia, como espacio y dinámica de construcción de sentidos, de deliberación y de toma de decisiones, se constituye en la forma privilegiada de la política (Svampa, 2007). Sin embargo, la tendencia a la desinstitucionalización convive con las experiencias de institucionalización alternativa: asambleas, "Caracoles", Juntas de Buen Gobierno, gobiernos locales, hasta nuevas dimensiones o formas del Estado (los Consejos Comunales en Venezuela o el Estado plurinacional en Bolivia). Asimismo, se resaltan las prácticas más igualitarias y fraternas entre distintos movimientos sociales expresadas en los foros, las coordinadoras, los frentes, las mingas, las plataformas, etc. Por otra parte, los nuevos movimientos sociales latinoamericanos combinarían formas de acción antagonistas, es decir confrontativas, con experiencias autónomas, es decir de autodeterminación.

Para algunos autores, en el desarrollo de estas prácticas democráticas, los movimientos construyen una estrategia política de la transformación de la sociedad, que les permite "cambiar el mundo sin tomar el poder" (Holloway, 2002). Esta posibilidad supone repensar la táctica y la estrategia del movimiento obrero tradicional; y repensar la conceptualización del poder, pasando de una noción del mismo marcada por la capacidad de imponer voluntades a otros, como "poder sobre", hacia una consideración democrática del mismo, como "poder hacer". En este sentido, los movimientos construirían contrapoderes o anti-poderes, enfrentados al poder estatal (Holloway, 2001c). Desde esta perspectiva, Holloway (2001 y 2001b) denuncia la "ilusión estatal" presente en la orientación de la izquierda tradicional y del movimiento obrero clásico. Frente a ella, los movimientos sociales latinoamericanos de las últimas dos décadas estarían ejerciendo y proponiendo nuevas formas de hacer política, que permitirían superar 
tendencialmente la escisión, liberal, entre lo político y lo social, y denunciar la fetichización de la política, que se produce cuando ésta se reduce a la "representación" de lo social.

Con todo, esta lectura que gozó de amplio reconocimiento, se ha visto confrontada en la práctica por la experiencia de muchos movimientos sociales que no abandonaron la lucha electoral y la disputa estatal y que, aún más, construyeron instrumentos políticos propios para disputar el poder también en esos espacios. Otros autores han aceptado criticar ciertos determinismos y "desviaciones" contenidas en la configuración histórica del movimiento obrero y de la izquierda tradicional, sin renunciar por ello a la disputa del poder estatal, entendiendo que el Estado sigue siendo la herramienta fundamental de la estrategia capitalista y por lo tanto también un elemento cardinal para las luchas por la transformación de la sociedad (por ejemplo, Boron, 2001). Desde esta perspectiva, se ponen de manifiesto las dificultades de las prácticas autónomas y autogestionarias para influir, de manera efectiva, en las políticas económicas, sociales, etc. y para articular proyectos amplios de transformación de la sociedad, que vayan más allá de espacios marginales (guetos) de resistencia defensiva.

El debate entre autonomismo y hegemonismo ha sido posiblemente el debate político más álgido del cambio de época y sus reverberaciones teóricas tuvieron y no dejan de tener relevancia. Frente al carácter radicalmente antiestatal de la postura autonomista -bosquejada más arriba-, otros intelectuales (entre ellos, Sader, 2008 y 2011, y García Linera, 2009b) defienden la oportunidad histórica que supone el proyecto hegemónico nacional-popular, del que los llamados gobiernos "progresistas" son expresión, y la pertinencia de la disputa estratégica del Estado para los proyectos de emancipación. Desde su perspectiva, la construcción de una nueva hegemonía se erige en la cuestión central de la etapa actual y, para ello, los partidos políticos y la disputa electoral siguen siendo componentes fundamentales, en la medida en que permiten proyectar la lucha al plano nacional y articular una estrategia de ocupación de espacios de poder que permiten transformar efectivamente las estructuras de la sociedad y refundar el Estado. En ese sentido, critican las formulaciones teóricas que enfatizan la autonomía de los movimientos sociales y rechazan la organización partidista y la disputa por la hegemonía porque, a su juicio, con esa postura renuncian a construir alternativas políticas capaces de producir transformaciones significativas, refugiándose en el plano de la resistencia defensiva. 


\section{GIROS Y TENDENCIAS}

Nutriéndose de este haz de debates temáticos, el análisis de los movimientos sociales en estas últimas décadas parece caracterizarse, en positivo, por los siguientes giros y tendencias teóricas:

1) Las ciencias sociales latinoamericanas han reconocido una gran importancia a los movimientos sociales. Éstos han dejado de ser declarados inexistentes o vistos como reacciones secundarias intrasistémicas y han adquirido una nueva centralidad en el estudio de los procesos políticos. En algunas interpretaciones, los movimientos sociales han sido redefinidos como los auténticos constructores de la sociedad, y como los verdaderos protagonistas de la Historia, de manera que la trasformación social pasaría necesariamente por el fortalecimiento de sus capacidades autónomas y autogestionarias. Desde otras posturas, menos optimistas respecto de sus capacidades democratizadoras, se ha destacado el rol desempeñado por los movimientos sociales en la crisis de legitimidad del neoliberalismo, señalando asimismo su dificultad para articular proyectos políticos amplios y para consolidar transformaciones sociales de gran calado.

2) En los análisis latinoamericanos ha tomado fuerza la dimensión simbólica de los movimientos sociales, esto es, la construcción de sentido que los activistas organizan respecto de las motivaciones de su participación y de la configuración de marcos de interpretación sobre las relaciones sociales, la relación con la naturaleza, la vida digna, el poder y la política. Esto ha permitido tanto desplazar relativamente la hipótesis economicista de la teoría de movilización de recursos como pasar de una constitución identitaria por desposesión (aquello de lo que carecían: los sin tierra, sin techo, sin trabajo, etc.) hacia una constitución afirmativa de su identidad. También se ha hecho hincapié en la "novedad" evidenciada en las prácticas de organización y de acción, más horizontales y de acción directa.

3) Subyace en la producción latinoamericana un enfoque multidimensional tendencialmente en construcción, que sin llegar a integrar orgánicamente las distintas facetas de los movimientos sociales, busca 
avanzar en su comprensión a partir de privilegiar ciertas dimensiones de los conflictos: el anclaje territorial, la dimensión comunitaria, ciertos elementos de la cosmovisión indígena, el cuestionamiento de la idea de "desarrollo", la acción directa, la democracia de base, otras formas de hacer política, etc. Si bien todas estas dimensiones no aparecen explícitamente organizadas en una "teoría" para comprender los nuevos movimientos sociales latinoamericanos, convergen hacia una suerte de paradigma de la acción colectiva y la transformación social.

4) Esta comprensión compleja de los movimientos sociales está convocando a intelectuales de algunas disciplinas -geografía, antropología, historia, psicología social, etc.- que tradicionalmente no se habían ocupado de su estudio, lo que sugiere la necesidad de abordar de manera interdisciplinaria el problema de la acción colectiva y el conflicto sociopolítico, que durante mucho tiempo permaneció como rama y coto exclusivo de la sociología.

5) El retorno de un "paradigma" del conflicto, la aceptación generalizada de su carácter irreductible y de las dimensiones estructurales y culturales que subyacen a a la emergencia y desarrollo de los movimientos sociales, desbancando el paradigma anterior que se había centrado en el carácter consociativo de la democracia, en el privilegio de la función representativa de la misma, en la tecnificación y consideración a-conflictiva de la política, y en una idea liberal de la ciudadanía. La dimensión conflictual (antagonista) de la constitución de subjetividades políticas permite tender puentes entre la noción de movimiento social y la de clase social, al subrayar en ambas el carácter relacional y procesual.

6) En efecto, impera una idea del movimiento social como proceso y como un conjunto de relaciones, en detrimento de una concepción más estructuralista del mismo. Sin desconocer el efecto de los factores estructurales, parece haberse impuesto una idea de las identidades, no esencialista, que entiende que no hay sujetos pre-constituidos, sino que éstos se constituyen en el conflicto, en la lucha. 
7) Al mismo tiempo, hay una tendencia a superar la escisión entre medios y fines, al concebir a los movimientos sociales como portadores de un mundo nuevo, abandonando una idea instrumental, pragmática o táctica de los mismos. En este sentido, los movimientos no se agotan en lo que demandan, no son puro cálculo, ni mera reivindicación o apelación al Estado o a los partidos políticos, sino construcción y afirmación de relaciones sociales alternativas; su existencia y su morfología conllevan una reivindicación que interpela la configuración del poder en la sociedad y que prefigura el mundo que pretenden construir. Hay una idea de los movimientos como más proactivos, más afirmativos y más estratégicos.

8) Por último, destacamos una actitud especialmente vigilante, en el pensamiento social latinoamericano, respecto de la posibilidad de incurrir en "desviaciones eurocéntricas". La tensión entre el "colonialismo del saber" y la preocupación por producir pensamientos propios que recojan y den cuenta de la especificidad de la región ha sido una de las constantes de la sociología latinoamericana. Y ha estado en la base de los esfuerzos de teorización más significativos (como la teoría de la dependencia o la filosofía de la liberación). En ese sentido, se afianzó en las ciencias sociales críticas latinoamericanas la preocupación por formar un pensamiento decolonial, esto es, por descolonizar o emancipar el pensamiento social latinoamericano en contenidos y formas y por erigir bases epistemológicas "nuevas", que pueden no obstante tener una larga tradición (como sucede con la recuperación de las matrices comunitario-indígenas o nacional-populares), construyendo un pensamiento desde el Sur (Santos, 2009) que desafía los límites y cuestiona las concepciones del pensamiento científico occidental. Desde esta perspectiva se busca tomar distancia de viejos conceptos y acuñar nuevos términos, o recuperar otros anteriormente marginados, resignificándolos.

\section{LOS LÍMITES DEL CAMBIO DE ÉPOCA: CONSIDERACIONES GENERALES E HIPÓTESIS DE TRABAJO}

Las tendencias de los estudios sobre los movimientos sociales, que hemos tratado de sintetizar más arriba, dan cuenta del proceso de aggiornamento 
que ha vivido el pensamiento social latinoamericano al calor del reciente ciclo de movilización sociopolítica. A la par de una abundante producción, caracterizada por cierto énfasis descriptivo que podría ser indicativo de la necesidad de documentar experiencias relativamente novedosas en los distintos contextos nacionales y en el ámbito regional, encontramos sugerentes planteamientos teóricos que impugnan tesis "clásicas" sobre la acción colectiva y la transformación social y abren campos de reflexión tendencialmente fértiles para renovar el pensamiento crítico, pero que, al mismo tiempo, revelan una insuficiente, quizás embrionaria aún, robustez teórica.

En efecto observamos que esos esfuerzos padecen de cierta discontinuidad en la reflexión, quedando los debates en muchas ocasiones truncos sin haber agotado sus posibilidades interpretativas, cuando ya emergen nuevas problemáticas que concitan y distraen la atención de los analistas. Ciertamente, la tensión entre las urgencias del presente y los requerimientos de una reflexión sosegada y metódica parece haber influido, momentáneamente, en esas interrupciones o intermitencias de la reflexión, pero ésa no parece ser la única, ni aun la principal, explicación. La persistencia de ciertas dinámicas institucionales, la negación de las contribuciones del marxismo crítico y la emergencia de posturas intelectuales que reaccionan críticamente frente a las posibilidades de la teoría, concurren a explicar el hecho de que no encontremos en la producción latinoamericana reciente un esfuerzo de sistematización y articulación de proposiciones que configure, de forma manifiesta, uno o diversos paradigmas alternativos para la comprensión de los movimientos sociales y políticos, sino sucesivas aproximaciones a una misma problemática que no siempre dejan un saldo acumulativo. Lo más cercano a una propuesta integral pudo ser la proliferación y convergencia de postulados en torno a un paradigma autonomista en el primer lustro del 2000, que se nutría de los elementos novedosos que enlistamos anteriormente, tratando de articularlos y proyectarlos. Al mismo tiempo, al estar íntimamente atado al ciclo de ascenso de los movimientos y a un formato específico de los mismos, dicho "paradigma emergente" entró en reflujo con el agotamiento de aquéllos, en el marco del giro progresista a nivel institucional y gubernamental, justamente en los países en donde más fuerza y arraigo había tenido. Por lo demás, por razones ligadas a la desconfianza respecto de la sistematización teórica, que revisaremos más adelante, y por su carácter fragmentario y disperso, la corriente autonomista nunca fue tal a nivel intelectual. 
El carácter parcial, intermitente, e insuficientemente desarrollado de algunas de las teorizaciones más sugerentes de la producción latinoamericana sobre movimientos sociales, plantea ciertos interrogantes acerca de la manera como los investigadores están comprendiendo tanto su labor intelectual como la realidad sobre la que reflexionan. Si bien no pretendemos desconocer la riqueza interpretativa y el potencial crítico contenido en las aperturas problematizadoras de los análisis latinoamericanos, consideramos indispensable llamar la atención sobre ciertas inercias institucionales y determinadas posturas epistemológicas que pudieran estar frenando la emergencia de fuertes y sólidas apuestas teóricas.

INERCIAS DE LA ACADEMIA

Al interrogarnos sobre las perspectivas teóricas para el estudio de los movimientos sociopolíticos en América Latina, debemos considerar tanto las características de dichos movimientos como las condiciones históricas en las que se produce el conocimiento, en la academia y fuera de ella. De hecho, la proliferación de espacios de autorreflexión configurados desde los propios movimientos sociales, cuyas preocupaciones teóricas no siempre se engarzan con las teorizaciones originadas en los ámbitos universitarios ha contribuido a impugnar la centralidad de la "forma universidad" como el único locus del conocimiento legítimo. ${ }^{7}$

Pero si nos circunscribimos al ámbito académico, constatamos diferencias significativas en los procesos de institucionalización y desarrollo de las ciencias sociales en los distintos países, que hacen que la heterogénea amplitud, estabilidad y tradición de las comunidades académicas nacionales sea un factor a tener en cuenta a la hora de valorar los alcances y límites

\footnotetext{
7 Varios estudios han señalado como algo característico de los movimientos sociales latinoamericanos recientes su capacidad para formar a sus propios intelectuales, desplegando y profundizando las prácticas de autoeducación popular (Zibechi, 2003). Entre las nuevas figuras intelectuales, Svampa (2007b) ha definido la del intelectual anfibio, que se mueve en dos "hábitats", el campo académico y el campo del activismo, sin confundirlos y sin renunciar a la especificidad de cada uno. Otros autores reivindican simplemente el retorno del "intelectual orgánico" de los movimientos sociales. Más allá del "nombre", las nuevas figuras intelectuales se caracterizarían precisamente por tener una vinculación con los movimientos sociales mucho más estrecha que en la etapa anterior, cuando la figura del "intelectual comprometido" fue anatemizada y expulsada de la academia. Estos intelectuales tienden a reflexionar teóricamente sobre su propia práctica militante y la de las organizaciones y movimientos en los que participan.
} 
de su producción intelectual. No obstante, la influencia de estos elementos en la capacidad de renovar el pensamiento crítico puede ser ambivalente: de un lado, la existencia de instituciones sólidas y tradiciones de pensamiento estables, proporciona recursos materiales e intelectuales para la reflexión y la producción académicas; de otro, el arraigo y la consolidación de ciertos paradigmas -que no solo ofrecen aparentes certezas ontológicas sino que son plataformas para carreras académicas- puede suponer una dificultad para formular nuevas interpretaciones -aunque las existentes no den cuenta cabalmente de las realidades circundantes-o para reconocer e incorporar las concepciones novedosas que son sugeridas por las mismas prácticas de los movimientos sociales. Nos encontramos, en este caso, frente a ciertas inercias que obstaculizan la elaboración de nuevas teorías.

Parece pesar también, en este diagnóstico, un componente generacional que permite ponderar el hecho de que la mayoría de los académicos que han venido produciendo análisis sobre los movimientos sociales se han formado o asentado intelectualmente en las décadas precedentes a la irrupción movimientista, bajo el peso del pensamiento conservador, del institucionalismo politológico y, en todo caso, bajo el influjo de los principales paradigmas europeos y norteamericanos de la acción colectiva. De hecho, la preocupación académica por los movimientos sociales emergió en América Latina en el contexto de la contrarrevolución de las décadas de los '70 y ' 80 , y en relación con los procesos de transición a la democracia y a contraflujo del ciclo de movilización revolucionaria de las décadas de los ' 60 y '70. A la preeminencia de la "sociología de la acción" de Alain Touraine, en la sociología latinoamericana de los años ochenta, le ha sucedido el influjo de las teorías norteamericanas de los movimientos sociales -la Teoría de Movilización de Recursos y la de las Estructuras de Oportunidad Política, fundamentalmente- en años más recientes. ${ }^{8}$

En todo caso, tras una primera etapa de recepción predominantemente a-crítica de esos enfoques, que redundó a la postre en cierta insatisfacción entre los científicos sociales por la inadecuación entre los movimientos sociales latinoamericanos y los postulados de aquellas teorías, y que demostró la insuficiencia para el caso latinoamericano de los conceptos con los que se trató de pensar la transformación social y los sujetos encargados

8 También ha ganado peso el paradigma de la identidad, a partir de la obra, principalmente, de Melucci; y, más recientemente, el marco de análisis de la política contenciosa (Tilly y Tarrow). 
de producirla, se constata que los enfoques europeos y norteamericanos siguen siendo referidos en la gran mayoría de las investigaciones sobre movimientos sociales, aunque en muchas de ellas se busca una distancia crítica, un uso fundamentalmente instrumental de sus categorías y se adopta una actitud tendencialmente creativa en su aplicación a los estudios empíricos. ${ }^{9}$ En el caso de la TMR y de la EOp, la relativa flexibilidad y fácil operacionalización de sus categorías fundamentales facilita, sin duda, su apropiación y reproducción en el examen de los movimientos sociales latinoamericanos, pero no siempre dichos análisis van acompañados de una reflexión más profunda sobre los presupuestos epistemológicos y teóricos y la carga valorativa que subyacen a aquellas categorías.

Es decir, ciertas características de las dinámicas de institucionalización de las ciencias sociales en América Latina, así como la configuración de los espacios académicos, el factor generacional y la preeminencia en la academia latinoamericana de los enfoques europeos y norteamericanos sobre movimientos sociales configuran un conjunto de variables a tener en cuenta en el "rendimiento teórico" de la producción sobre movimientos sociales y, específicamente, en la explicación de la atrofia relativa de la capacidad de renovación y creación de nuevos conceptos y enfoques.

\section{CRÍTICA DE LA RAZÓN TEÓRICA}

El surgimiento de una actitud crítica frente a las teorías sobre movimientos sociales, construidas en relación con otros contextos socioculturales $y$ en las cuales la especificidad latinoamericana nunca ha resultado bien representada y explicada, ha reforzado la necesidad de construir un pensamiento propio, desde y para América Latina.

Al mismo tiempo, una tendencia extrema de ese pensamiento decolonial ha buscado invalidar el propio concepto de movimiento social por proceder de la matriz moderna del pensamiento occidental. En efecto, las perspectivas decoloniales y el énfasis en la construcción de un pensamiento genuino y original, han comportado no sólo la impugnación de los productos intelectuales de "occidente" sino también de las formas de construir

9 Bringel (2011) refiere, para el caso brasileño, que la recepción de las teorías norteamericanas ha sido indirecta, tardía y parcial. Es a través de ciertos autores nacionales que difunden dichas teorías en sus trabajos, y que fungen como "mediadores", que las nuevas generaciones se apropian de ellas. 
conocimiento y de las bases epistemológicas sobre las que éste se erige. ${ }^{10} \mathrm{El}$ cuestionamiento de la ciencia moderna y de sus efectos clasificatorios y de "control" -que bebe, a su vez, de tradiciones críticas del pensamiento occidental (Foucault, Bourdieu, etc.) - y la denuncia de una suerte de "miseria de la teoría" (E. P. Thompson), se ha traducido en una actitud de sospecha y de resistencia frente a las operaciones teóricas de abstracción, categorización, definición, ordenamiento, jerarquización, clasificación, etc. En definitiva, en un rechazo de los sistemas, incluidos los teóricos.

A partir de una crítica justa y necesaria sobre ciertas rigideces y unilateralismos de algunos modelos teóricos -o de los intelectuales en su aplicación- y del reconocimiento, acertado, de la insuficiencia de cualquier teoría para dar cuenta de la multiplicidad de aristas y dimensiones de los problemas sociales, algunos autores y cierto sentido común que lograron generar en determinados ambientes académicos e intelectuales han transitado hacia una negación absoluta de la necesidad o de la posibilidad de establecer marcos teóricos sobre la realidad latinoamericana y, particularmente, sobre los movimientos sociopolíticos. Esta conclusión deriva tanto de la constatación empírica, incontrastable, que evidencia la fragmentación y la diversidad de experiencias de protesta y de movilización y dificulta su "acomodo" en categorías analíticas abstractas sin menoscabar su capacidad explicativa; ${ }^{11}$ como de un cuestionamiento sobre la ciencia moderna y las formas de producir conocimiento, que pone en cuestión la propia noción de teoría y la utilidad -para los propios proyectos emancipatorios- de sus operaciones de análisis y síntesis.

Es precisamente en relación con la "utilidad" de la teoría para los movimientos sociales que prevalece una actitud de recelo entre los intelectuales latinoamericanos críticos. A contramano de orientaciones políticas clásicas del pensamiento social que postulaban la relevancia de la teoría para "orientar" la acción política, de los análisis recientes sobre movimientos sociales se desprende una arraigada desconfianza o escepticismo frente

10 La "epistemología del Sur" de Boaventura de Sousa Santos constituye un referente obligado de esta nueva actitud ante la producción de saberes.

11 De esta manera, algunos autores reconocen la "imposibilidad" de proponer una teoría de los movimientos sociales, toda vez que ellos son inacabados, procesuales, fragmentados, particulares, etc. (Gohn, 1997; Zibechi, 2008). Y que son portadores de nuevos sentidos que no están plenamente cristalizados, de ahí la dificultad de "captarlos". Desde esta lectura, se construye una concepción, no siempre explícita, del movimiento social y de la construcción de subjetividades políticas como procesos, eminentemente cambiantes y relacionales, que dificulta su cristalización en categorías más o menos fijas (Santos, 2001: 178). 
a la "operación teórica", que parece constituir antes un impedimento que una necesidad, para el despliegue de las potencialidades del propio movimiento, al fijarlo en un momento, detenerlo y/o esclerotizarlo. Desde esta perspectiva, lo que es movimiento no puede ser teorizado. Frente a una supuesta hipertrofia de la teoría en el pasado, los nuevos estudiosos de los movimientos sociales propugnan una actitud de mayor "respecto" frente a las propias interpretaciones y cursos de acción del movimiento, ya que cualquier intento de definir, comporta un "cierre" de sus capacidades. El elogio de la "indefinición" - como la facultad del propio actor de no dejarse "encasillar", que sería la antesala de su manipulación y control desde las instancias de gobierno- es, aquí, expresión de su poder antisistémico, de su capacidad de subvertir la lógica moderna.

En este antiteoricismo, acompañado de cierto antiintelectualismo, ampliamente difundido entre franjas importantes de científicos sociales latinoamericanos, ha influido indudablemente el uso que tradicionalmente los poderes conservadores han hecho de la academia y de la investigación científica. El financiamiento de agencias gubernamentales y privadas de los países del Norte para investigar a los movimientos sociales latinoamericanos y su injerencia en las agendas de investigación de las ciencias sociales regionales, no es algo nuevo y, por lo mismo, oponerse a ese imperialismo (y al "colonialismo -interno- del saber") constituye un "sentido común" largamente incorporado en algunas tradiciones de pensamiento crítico. ${ }^{12} \mathrm{~A}$ su vez, la comprobación de la existencia de una academia "aislada" de las luchas sociales y políticas, cuyo afán de teorización no siempre se articuló con proyectos de transformación concretos, reforzó la idea de que la teoría, como abstracción y "contemplación", no tenía una utilidad práctica para los movimientos sociales.

Con todo, no puede desconocerse que la crítica de la razón teórica involucra dos riesgos: de un lado, la pretensión, inocente, de que es posible aprehender la realidad sin nociones preconcebidas de la misma incurriendo

$12 \mathrm{Al}$ menos desde que se hiciera público, a mediados de la década del sesenta, el "proyecto Camelot", un ambicioso programa de financiamiento del gobierno estadounidense a científicos sociales latinoamericanos, cuyo propósito era investigar sobre los movimientos populares y los proyectos revolucionarios para socavar sus bases y desarticularlos, en las ciencias sociales críticas ha habido una reticencia, justificada, a proporcionar elementos de análisis que pudiera servir a fines de control y aniquilación de esas experiencias transformadoras. El estudio sobre los movimientos sociales se constituye, sin lugar a dudas, en "material sensible". 
en el error de no ser capaz de percibir la influencia de nuestros prejuicios en el proceso de observación y comprensión; y, de otro, el peligro de producir un nuevo unilateralismo para explicar los problemas sociales (como sucede a menudo con el énfasis en la dimensión cultural de los movimientos sociales, en detrimento de los factores económicos o políticos), desconociendo, tácitamente, la complejidad, en nombre de la cual se había paradójicamente justificado el abandono de los paradigmas precedentes.

\section{NEGACIÓN DEL MARXISMO CRÍTICO}

A partir de la misma lógica, del cuestionamiento de la ciencia moderna y de los paradigmas occidentales, en convergencia involuntaria con la embestida del pensamiento liberal, se promovió la liquidación del marxismo no sólo como tradición teórica sino también como acervo susceptible de actualizar o de contribuir a la configuración de nuevas perspectivas críticas. Cabe señalar que la emergencia de los movimientos sociales como campo de investigación se produjo de la mano del "juicio al sujeto" (Guido y Fernández, 1990) -al movimiento obrero- que había enarbolado los proyectos revolucionarios de los '60 y '70, y a la par de la "crisis" del marxismo ortodoxo. En ese contexto, se generalizó en el pensamiento latinoamericano una actitud de reproche frente a un marxismo que había teorizado constantemente la subordinación de los distintos actores sociales -campesinos, sectores "marginales", etc.- a la dirección de la vanguardia obrera, del partido. Simultáneamente, asimilándolo y simplificando sus especificidades, se desecharon también las vetas del marxismo crítico, eventualmente purificándolas y convirtiéndolas en clave posmarxista. Nuevamente parece que, sobre un poso de verdad, que reconocía el mecanicismo y dogmatismo de algunas lecturas marxistas, una vertiente de las ciencias sociales operó una simplificación de la problemática subyacente y tiró el niño con el agua sucia. Se puede y debe reconocer que, en medio de la crisis político-ideológica, tanto por el desánimo surgido de la derrota del proyecto revolucionario como por el repliegue que efectivamente sufrieron estos fenómenos, las mismas vertientes del marxismo crítico perdieron vitalidad y desatendieron el esfuerzo teórico de sostener y renovar el análisis de las problemáticas de formación de subjetividades políticas y de movilización social y política. Al mismo tiempo, el abandono de la agenda y el acervo conceptual del marxismo se tradujo en 
el desplazamiento del análisis desde una perspectiva que combinaba la atención hacia la estructura y la acción, el sistema y el sujeto, hacia enfoques fragmentarios, predominantemente culturalistas o institucionalistas. No es casual -ni indiferente respecto a la capacidad de renovación teórica que invocamos- la simultaneidad entre la difusión de los paradigmas de análisis de los movimientos sociales y la "crisis" del marxismo a partir de mediados de los años '70.

Sin embargo, a contrapelo de estas tendencias, el marxismo latinoamericano, aún en versiones que no emprenden explícita y sistemáticamente su renovación, ha venido experimentado, desde la década de los noventa, una sostenida revitalización, que se pone de manifiesto en el surgimiento o reedición de revistas, en la multiplicación de seminarios y cursos de análisis de inspiración marxista, en la publicación de trabajos que recuperan corrientes o conceptos marxistas, etc. Con todo, el retorno del pensamiento marxista a los debates actuales no ha producido, aún, una renovación de la teoría sobre la movilización social y política, ni como perspectiva propia o neomarxista ni en clave de aportaciones decisivas a otras empresas teóricas. Los principales aportes marxistas para repensar la acción política y el proceso de subjetivación que le corresponde se han producido fundamentalmente en el ámbito de la filosofía y no siempre tienen fácil traducción en el examen concreto de movimientos sociopolíticos, y en la propia orientación política de éstos, acarreando nuevamente el riesgo de un divorcio entre la teoría y la praxis. A pesar de que el análisis de los movimientos sociales se haya constituido hasta ahora como un terreno inexplorado -o insuficientemente examinado- por los teóricos marxistas, existen esfuerzos recientes para construir una perspectiva específicamente marxista o, si se quiere neomarxista, para el análisis de los movimientos sociopolíticos y la subjetividad política (Modonesi, 2010, 2013 y 2015).

\section{REFLEXIONES FINALES}

En definitiva, para explicar el hecho de que tras una década de movilizaciones sociopolíticas amplias, diversas y profundas, no hayan emergido ejercicios o apuestas de teorización fuerte y de amplio alcance sobre los movimientos sociales -a pesar de la manifiesta insatisfacción con los enfoques y teorías existentes, y de la emergencia de sugerentes discusiones y problematizaciones teóricas- no es posible aventurar una única razón 
o identificar una sola causa sino que se requiere poner en discusión un conjunto de variables que pueden estar sobredeterminando ese circunstancia. Aquí hemos aventurado algunas hipótesis iniciales en relación con ciertos factores históricos y estructurales de la configuración de las ciencias sociales en la región, y con actitudes y posturas epistemológicas y políticas de los académicos críticos latinoamericanos que traslucen una nueva conceptualización sobre los movimientos sociales y la construcción del conocimiento.

Recapitulando nuestro ejercicio de balance, valoramos los elementos y las tendencias que surgieron del clima de época, aunque consideramos que éstos no tienen la consistencia, la articulación y la proyección suficientes para configurar una ruptura paradigmática respecto de la persistente influencia de los enfoques dominantes, en particular los de origen norteamericano. Si bien no se trata de una década perdida para el pensamiento latinoamericano, no quisiéramos que resultara ser una oportunidad perdida, siendo que tanto el ciclo de ascenso como de reflujo de los movimientos socio-políticos a escala regional constituyó un piso histórico socio-político de extraordinario valor como horizonte de observación susceptible de estimular ejercicios de generalización y abstracción que pudieran desembocar en novedosas propuestas teóricas.

En ese sentido, por el desfase propio de la decantación teórica respecto de la inmediatez de la experiencia histórica, quizás se requiera de la maduración teórica de las generaciones más jóvenes que, de forma masiva, entusiasta y no pocas veces teñida de un saludable ethos militante, se dedicaron a estudiar a los movimientos sociales que marcaron el cambio de época. Siempre y cuando no sean absorbidos por las inercias academicistas y se atrevan a pensar más allá de los paradigmas existentes, que siguen siendo hegemónicos y se reproducen en los salones de clases, los pasillos y los cubículos de nuestras universidades de este sur del mundo.

\section{BIBLIOGRAFÍA}

ANTUNES, R. (2013); Los sentidos del trabajo. Ensayo sobre la afirmación y la negación del trabajo. Buenos Aires: Herramienta.

BARTRA, A. (2010); "Campesindios. Aproximaciones a los campesinos de un continente colonizado", en Memoria, Revista de Política y Cultura, 248, pp. 4-13.

BORON, A. (2001); "La selva y la polis. Reflexiones en torno a la teoría política del zapatismo", en OSAL, 4 (Junio), pp. 177-186. 
BRINGEL, B. (2011); "A busca de uma nova agenda de pesquisa sobre os movimentos sociais e o confronto politico: diálogos com Sidney Tarrow [Comentários ao artigo de Sidney Tarrow”, en Política \& Sociedade, 10, 18, pp. 51-73.

BRUCKMANN, M. y DOS SANTOS, T. (2005); "Los movimientos sociales en América Latina: Un balance histórico”. bibliotecavirtual.clacso.org.ar/ar/ libros/reggen/pp13.pdf (19 de junio de 2015).

CECEÑA, A. E. (2002); "Rebeldías sociales y movimientos ciudadanos", en OSAL, 6 (Enero), pp. 11-16. (2008); "El mundo desde el universo zapatista", en A. E. Ceceña, Derivas del mundo en el que caben todos los mundos. México: Clacso / Siglo XXI, pp. 63-92.

DÁVALOS, P. (2005); "Movimientos indígenas en América Latina: El derecho a la palabra”, en P. Dávalos (ed.), Pueblos indígenas, Estado y democracia. Buenos Aires: Clacso, pp. 17-33.

FEDERICI, S. (2010); Calibán y la bruja. Mujeres, cuerpo y acumulación originaria. Madrid: Traficantes de Sueños.

GARCÍA LINERA, Á. (2001); "Sindicato, multitud y comunidad. Movimientos sociales y formas de autonomía política en Bolivia”, en A. García Linera, R. Gutiérrez, R. Prada y L. Tapia, Tiempos de rebelión. La Paz: La Muela del Diablo, pp. 9-82.

, (2009); Forma valor y forma comunidad. Aproximación téorica-abstracta a los fundamentos civilizatorios que preceden al Ayllu Universal. La Paz: Clacso / La Muela del Diablo / Comuna.

(2009b); La potencia plebeya. Acción colectiva e identidades indígenas, obreras y populares en Bolivia (antología y presentación de Pablo Stefanoni). Buenos Aires: Prometeo / Clacso.

GIARRACA, N. (2012); “Tres paradojas para repensar la política”, en G. Massuh, Renunciar al bien común. Extractivismo y (pos)desarrollo en América Latina. Buenos Aires: Mardulce, pp. 191-235.

GOHN, M. G. (1997); Teorias dos movimientos sociais: paradigmas clássicos e contemporâneos. São Paulo: Loyola.

GONZÁLEZ CASANOVA, P. (2002); “Democracia, liberación y socialismo: tres alternativas en una”, en OSAL, 8 (Septiembre), pp. 175-180.

, (2009); “Los 'Caracoles' zapatistas: redes de resistencia y autonomía (ensayo de interpretación)", en M. Roitman, De la sociología del poder a la sociología de la explotación: pensar América Latina en el siglo XXI. Pablo González Casanova. Bogotá: Siglo del Hombre / Clacso, pp. 335-354.

GUIDO, R. y O. FERNÁNDEZ (1990); "El juicio al sujeto: un análisis de los movimientos sociales en América Latina”, en I. Wallerstein y otros, El juicio al sujeto. Un análisis global de los movimientos sociales. México: Flacso-México / Porrúa, pp. 117-170. 
GUTIÉRREZ, R. (2009); Los ritmos del Pachakuti. Levantamiento y movilización en Bolivia (2000-2005). México: Bajo Tierra.

HARVEY, D. (2004); El nuevo imperialismo. Madrid: Akal.

HOLLOWAY, J. (2001); "El zapatismo y las ciencias sociales en América Latina”, en OSAL, 4 (Junio), pp. 171-176.

, (2001b); "La asimetría de la lucha de clases. Una respuesta a Atilio Boron”, en OSAL, 4 (Junio), pp. 187-188.

, (2001c); “Doce tesis sobre el Anti-Poder", en E. Fontana et al. (eds.), Contrapoder. Una introducción. Buenos Aires: De mano en mano, pp. 73-82. (2002); Cambiar el mundo sin tomar el poder. El significado de la revolución hoy. Puebla / Buenos Aires: Benemérita Universidad Autónoma de Puebla / Herramienta.

IGLESIAS, M. (2011); “Teoría en movimiento: más de una década de pensamiento crítico", en OSAL, 30 (Noviembre), pp. 25-42.

MODONESI, M. (2008); “Crisis hegemónica y movimientos sociales en América Latina. Una lectura gramsciana del cambio de época”, en A contracorriente, 5, 2, pp. 115-140.

, (2010); Subalternidad, antagonismo, autonomía. Marxismos y subjetivación política. Buenos Aires: Prometeo / Clacso / Universidad de Buenos Aires.

, (2013); "Marxismo crítico y teorías de los movimientos sociales". www.proyectoantagonismo.com/proyecto.html (19 de junio de 2015).

, coord. (2015); Movimientos subalternos, antagonistas y autónomos en México y América Latina. México: Clacso / Facultad de Ciencias Políticas y Sociales (Universidad Nacional Autónoma de México).

OUVIÑA, H. (2002); "Las asambleas barriales y la construcción de lo "público no estatal": la experiencia en la Ciudad Autónoma de Buenos Aires", Informe final del concurso: Movimientos sociales y nuevos conflictos en América Latina y el Caribe. Buenos Aires: Programa Regional de Becas Clacso.

PARRA, M. A. (2011); "Características actuales de la movilización social en América Latina”, en $O S A L, 30$ (Noviembre), pp. 43-64.

PORTO-GONÇALVES, C. W. (2003); "A geograficidade do social: uma contribuição para o debate metodológico sobre estudos de conflito e movimentos sociais na América”, en J. Seoane (comp.), Movimientos sociales y conflictos en América Latina. Buenos Aires: Clacso.

, (2005); "A Nova Questão Agrária e a Reinvenção do Campesinato: o caso do MST", en OSAL, 16 (Enero-Abril), pp. 23-34.

(2008); "De saberes e de territórios: diversidades e emancipação a partir da experiência latino-americana”, en A. E. Ceceña (ed.), De los saberes de la emancipación y de la dominación. Buenos Aires: Clacso. 
PRADA, R. (2008); Subversiones indígenas. La Paz: Clacso / La Muela del Diablo / Comuna.

REBÓN, J. y MODONESI, M., comps., (2011); Una década en movimiento. Luchas populares en América Latina en el amanecer del siglo XXI. Buenos Aires: Clacso.

SADER, E. (2008); El nuevo topo. Los caminos de la izquierda latinoamericana. Buenos Aires: Clacso / Siglo XXI.

(2011); "Pensamento critico e hegemonia alternativa", en $O S A L, 30$ (Noviembre), pp. 13-18.

SANTOS, B. (2001); "Los nuevos movimientos sociales", en OSAL, 5 (Septiembre), pp. 177-188. , (2009); Una epistemología del Sur. La reinvención del conocimiento y la emancipación social. México: Clacso / Siglo XXI.

SEOANE, J. (2003); Movimientos sociales y conflictos en América Latina. Buenos Aires: Clacso.

, (2012); "Neoliberalismo y ofensiva extractivista. Actualidad de la acumulación por despojo, desafíos de Nuestra América”, en Theomai, 26 (Julio-Diciembre).

SEOANE, J., Taddei, E. y Algranati, C. (2011); "El concepto de 'movimiento social' a la luz de los debates y la experiencia latinoamericana recientes", en Controversias y Concurrencias Latinoamericanas, Revista de la Asociación Latinoamericana de Sociología, 3, 4, pp. 169-198.

(2006); "Las nuevas configuraciones de los movimientos populares en América Latina”, en A. Boron; G. Lechini (eds.), Política y movimientos sociales en un mundo hegemónico. Lecciones desde África, Asia y América Latina. Buenos Aires: Clacso, pp. 227-250.

SVAMPA, M. (2007); “Movimientos sociales y escenario político: Las nuevas inflexiones del paradigma neoliberal en América Latina”. www.maristellasvampa.net/archivos/ensayo38.pdf (19 de junio de 2015).

, (2007b); “¿Hacia un nuevo modelo intelectual?”, en N Revista de Cultura, 209 (Septiembre).

, (2008); Cambio de época. Movimientos sociales y poder político. Buenos Aires: Siglo XXI.

, (2010); "Movimientos sociales, matrices socio-políticas y nuevos escenarios en América Latina”, en Working Papers, OneWorld Perspectives, 1, pp. 1-26.

, (2012); "Consenso de los commodities, giro ecoterritorial y pensamiento crítico en América Latina”, en OSAL, 32 (Noviembre), pp. 15-38.

SVAMPA, M. y PEREYRA, S. (2003). Entre la ruta y el barrio. La experiencia de las organizaciones piqueteras. Buenos Aires: Biblos. 
TADDEI, E. (2002); “Enero-abril 2002. Crisis económica, protesta social y 'neoliberalismo armado’ en América Latina”, en OSAL, 7 (Junio), pp. 29-36.

TAPIA, L. (2008); Política salvaje. La Paz: Clacso / Coediciones La Paz.

VILAS, C. M. (1995); “Actores, sujetos, movimientos: ¿dónde quedaron las clases?", en Sociológica, 10, 28 (Mayo-Agosto), pp. 61-90.

ZIBECHI, R. (2003); “Los movimientos sociales latinoamericanos: tendencias y desafíos", en OSAL, 9 (Enero), pp. 185-188.

(2006); Dispersar el poder. Los movimientos como poderes antiestatales. Buenos Aires: Tinta Limón.

, (2007); Autonomías y emancipaciones. Lima: Programa Democracia y Transformación Global y Fondo Editorial de la Facultad de Ciencias Sociales (Universidad Nacional Mayor de San Marcos).

, (2008); "Dibujando fuera de los márgenes. ¿Movimientos sociales o sociedad en movimiento? En América Latina”, en S. Nuin. Entrevista a Raúl Zibechi. Buenos Aires: La Crujía. 